\title{
RESPONSABILIDAD CIVIL SOLIDARIA DEL TERCERO EN DIVOR- CIO POR CAUSAL DE ADULTERIO
}

\author{
PADY ISABEL MENDIZÁBAL GALLEGOS*
}

\section{RESUMEN}

El presente trabajo tiene por objetivo determinar si conforme a la responsabilidad solidaria el tercero coresponsable en un divorcio por causal de adulterio, con el cónyuge culpable, debe responder por el daño a la persona que se ocasiona al cónyuge inocente. Al respecto abordamos el tema en cuestión desde la responsabilidad civil extracontractual a partir de la culpa (culpa en sentido estricto) y dolo. Esto es, si en función a la culpa el tercero - amante, podría también ser responsable -junto con el cónyuge culpable- del daño que se le ocasiona al cónyuge inocente. Del mismo modo se desarrolla la co-autoría en la producción del daño y la consecuente responsabilidad solidaria del cónyuge culpable y del tercero -amante, en el entendido que el tercero es un autor y no un partícipe. El método de recolección de información que se utilizó en la presente investigación es la observación.

PALABRAS ClAVES: Adulterio, Divorcio, Responsabilidad Civil Extracontractual, Daño a la Persona.

\section{ABSTRACT}

This paper aims to determine whether joint liability under the third co-responsible in a divorce for the cause of adultery, with the guilty spouse must respond for the damages to the person that causes the innocent spouse.In regards we approach the subject matter from tort liability based on fault (fault in the strict sense) and fraud. That is, if the fault according to the third -lover, it could also be responsible-along with the guilty spouse-of the harm it causes to the innocent spouse. In the same way co-authoring takes place in the production and consequent damage several liability of the guilty party and the third -lover, with the understanding that the third party is an author and not a participant. The data collection method that was used in this present investigation is an observation.

KEY WORD: Adultery, divorce, tort liability, guilt, moral damage

\section{INTRODUCCIÓN}

Escasa importancia a merecido, en nuestro país, el tema del resarcimiento del daño moral y del daño al proyecto de vida matrimonial con ocasión del adulterio. Tanto es así que en la jurisprudencia nacional se encuentra algunas sentencias respecto del primero y ninguna respecto del segundo.

Por su parte, igual devenir ha tenido en la doctrina nacional. El tema que abordamos en el presente trabajo es referido a la solidaridad del tercero - amante y el cónyuge culpable respecto del resarcimiento del daño a la persona del cónyuge inocente, nos referimos al «daño a la persona» en la medida que

*Abogada con estudios de Maestría y Doctorado en Derecho en la Universidad Nacional del Altiplano - Puno.

Servidor Judicial adscrita al Primer Juzgado de Familia de la Corte Superior de Justicia de Puno. 
es una voz genérica y comprende daños como el «daño moral» y el «daño al proyecto de vida» entre otros.

La casuística local demuestra que cuando se produce un divorcio por adulterio, el cónyuge inocente -en algunos casos- demanda también resarcimiento del daño moral, el mismo que lo dirige contra el cónyuge culpable. En efecto ello sucede así porque nuestro Código Civil en su artículo $351^{\circ}$ así lo faculta; es por ello que, en el presente trabajo desarrollamos, si la demanda - en lo que respecta al resarcimiento- solo se debe de dirigir contra el cónyuge culpable 0 , si eventualmente se podría dirigir contra el tercero amante. Por lo que, a partir de la interrogante $¿ E I$ tercero co-responsable que provoca el divorcio en un matrimonio debe responder solidariamente con el cónyuge culpable por el daño a la persona que se ocasiona al cónyuge perjudicado? el presente trabajo tiene el objetivo, primeramente de determinar si conforme al art. 1969 del C.C. el tercero coresponsable del divorcio debe responder por el daño a la persona ocasionado al cónyuge inocente y consecuentemente determinar si conforme a la responsabilidad solidaria el tercero co-responsable con el cónyuge culpable debe responder por el daño a la persona que se ocasiona al cónyuge inocente.

Por otra parte, en cuanto a la justificación de la investigación, debemos indicar que el derecho no puede ser ajeno a una situación que se presenta en la realidad como la descrita anteriormente. Además se debe de tener en cuenta la importancia de la familia, la misma que constituye la base de la sociedad y que es deber del Estado proteger a la misma, esto último según mandato constitucional.

No se puede permitir que el daño ocasionado al cónyuge inocente -en un divorcio por causal de adulterio- no sea efectivamente resarcido y cuando se habla del resarcimiento no solo debe de responsabilizarse al cónyuge culpable, sino también al tercero o tercera que con dolo o culpa se interpone en la relación matrimonial y que contribuye al daño que se le ocasiona al cónyuge inocente.

Al hacerse responsable tanto al cónyuge culpable como al tercero o la tercera, se pretende que las personas que ocasionaron un daño a otra -cónyuge inocente- lo resarzan según las reglas de la responsabilidad civil extracontractual. De otro lado el cónyuge inocente tendrá mayores posibilidades de ver resarcido el daño que sufrió.

En las siguientes páginas se abordan los temas señalados anteriormente esperando con ello contribuir a un tema delicado como lo es el daño que se produce al cónyuge inocente como consecuencia del adulterio y su posterior divorcio, tema que como se tiene ya anotado ha sido poco desarrollado en la doctrina y jurisprudencia nacional.

\section{MATERIALES Y MÉTODO DE INVESTIGACIÓN}

La presente investigación corresponde al diseño de investigación cualitativa. El método de recolección de información que se utilizó en la presente investigación es la observación, en razón a que se efectuó un procedimiento de percepción atento, racional, planificado y sistemático de los fenómenos relacionados con el problema objeto de la investigación. Se utilizó la siguiente técnica: análisis documental. Por cuanto el objeto de estudio se encuentra contenido en normas jurídicas, en documentos y libros.

Se utilizó los siguientes instrumentos: Fichas bibliográficas, fichas documentales, fichas de jurisprudencia. En cuanto al Universo, la unidad de estudio, son: las normas jurídicas contendidas en el Código Civil; las Resoluciones judiciales del Poder Judicial del Perú; doctrina respecto al matrimonio, divorcio, la responsabilidad solidaria, la responsabilidad extracontractual subjetiva y el daño a la persona.

\section{DISCUSIÓN TEÓRICA Y RESULTADOS}

En nuestra realidad se puede observar una situación bastante peculiar respecto del resarcimiento, cuando se da el divorcio por causal de adulterio. En efecto, cuando se presenta un divorcio por esta causal, el cónyuge culpable debe de responder por el daño a la persona que se le ocasiona al cónyuge inocente, pero junto con el cónyuge culpable debe de responder el tercero que se interpone en la relación cuando este conocía la relación matrimonial o podía haberla conocido. Se puede afirmar entonces que en la práctica judicial se concede un resarcimiento al cónyuge inocente a cargo del cónyuge culpable del 
divorcio, particularmente en el caso del adulterio. Sin embargo, el tercero o la tercera que se interpone en la relación matrimonial no es considerada como responsable, consecuentemente no se encuentra constreñida a resarcir el eventual daño.

Nuestro Código Civil en su artículo $351^{\circ}$ prescribe que: «Si los hechos que han determinado el divorcio comprometen gravemente el legítimo interés personal del cónyuge inocente, el Juez podrá concederle una suma de dinero por concepto de reparación del daño moral». Como se podrá advertir el Código Civil reconoce el daño moral al cónyuge inocente; sin embargo, el mismo solo es de cargo del cónyuge culpable, existiendo -a nuestro criterio- una tercera persona que junto con él es también responsable del adulterio y consecuente daño al cónyuge inocente.

\subsection{Situación Actual en el Perú sobre Divorcio por Adulterio y la Culpa del Tercero (amante)}

En la actualidad en el Perú no existe un caso, a saber, en donde a raíz de un proceso de divorcio por adulterio se haya demandado por daños a la persona (daño moral entre otros) al cónyuge culpable conjuntamente con el tercero (amante). Ello creemos- ocurre básicamente por dos aspectos: el primero viene configurado por la difícil probanza que amerita el adulterio y, el segundo, viene constituido por el hecho de simple omisión; esto es, no obstante pudiéndose probar el adulterio-eventualmente- solo se demanda daño moral al cónyuge culpable dejándose de lado a la amante.

Son estos aspectos aludidos los que desarrollaremos en los siguientes párrafos.

\subsubsection{Se tiene probado el adulterio pero se demanda divorcio por imposibilidad de hacer vida en común.-}

Expediente $\mathrm{N}^{\circ}$ 2004-02504-0-2101-JR-FA-2 (Divorcio por causal), En este caso la persona de N. F. P. interpuso demanda de divorcio por la causal de imposibilidad de hacer vida en común y separación de hecho y acumulativamente en forma accesoria las pretensiones de fenecimiento de la sociedad de gananciales, continuidad de la tenencia de sus hijos menores, en contra de P. V. A. P. (Divorcio por causal, 2004).

En un pasaje de la parte expositiva de la sentencia se sostuvo:

«Se debe de entender que el actuar del demandado en todo momento siempre fue malicioso, falso, ocasionándoles el sufrimiento que padecieron sus hijos y la recurrente, prueba de ello son los hijos extramatrimoniales que procreó el demandado con la hermana de la recurrente, hijos que a la fecha cuentan con veinticinco, veintiuno, trece años de edad respectivamente, extremo que acredita con las partidas de nacimiento respecto de los hijos extramatrimoniales concebidos por el demandado, las mismas que se anexan a la presente, se puede observar que el demandado cometió adulterio en forma reiterada ....».

En una parte del séptimo considerando se dijo:

«Que, de la prueba aportada por ambas partes, se advierte que el matrimonio ha sido una constante agresión entre ambos cónyuges, tal conforme se desprende de las constancias de garantías personales de folios dieciocho a veintidós, los cuales evidentemente hacen imposible mantener una vida en común, llegando inclusive el demandado a procrear hijos con la hermana de la demandante (...)».

En el considerando décimo se señaló:

«(...) Con relación al daño moral invocado de autos no se ha acreditado la existencia del daño moral presente, por cuanto la demandante en su oportunidad no ha realizado las denuncias pertinentes por el hecho de estar con su hermana a la vez».

En este caso se presentó claramente el supuesto de adulterio -el demandado tuvo 3 hijos extramatrimoniales- sin embargo; la causal invocada fue la de imposibilidad de hacer vida en común y no el adulterio, ello puede haberse presentado así probablemente porque se pudo estar inmerso en el artículo $336^{\circ}$ C.C.

De otro lado, respecto del daño moral el juez consideró que no estuvo acreditado, dado que la 
demandante no realizó la denuncia pertinente por el hecho del adulterio. Al respecto es necesario precisar que el daño moral es un daño in re ipsa; esto es, es un daño que se presume, que no puede ser materia de prueba directa, ergo no se puede acreditar el daño moral con una denuncia.

No obstante el divorcio se produjo por la causal de imposibilidad de hacer vida en común, es menester precisar que el «daño moral» -de haberse producidopudo haberse invocado por el adulterio considerado en sí mismo.

Así mismo, nótese que si -en el presente caso- la causa del divorcio hubiese sido el adulterio se pudo haber demandado por el eventual daño moral, al cónyuge culpable y a la amante (la hermana) que obviamente sabía el estado civil de ambos y a sabiendas de la existencia de una relación matrimonial pre existente sostuvo una relación extramatrimonial en donde se llegó hasta a procrear 3 hijos.

\subsubsection{Se demanda divorcio por la causal de adulterio pero posteriormente se varía la causal.-}

En este punto veremos algunas demandas en donde en un inició se demandó por la causal de adulterio y luego se varió la causal. No obstante, el divorcio se determina por una causal distinta a la del adulterio, es importante apreciar que al momento de demandarse no se invoca el daño moral o, si se invoca no se demanda al tercero (amante) respecto del mismo

\section{Expediente $\mathrm{N}^{\circ}$ : 2000-0226-21-2101-JF-01 (Divorcio por causal)}

El demandante B. G. E. S. interpuso demanda de divorcio por causal de adulterio y conducta deshonrosa y acumulativamente ejercicio de la patria potestad, tenencia y cuidado de sus menores hijos, demanda que la dirigió en contra de C. E. C. G. (Divorcio por causal, 2000)

En un pasaje de la parte expositiva se tuvo que:

«(...) que durante la convivencia se presentaron hechos que hicieron la vida en pareja insoportable, que fue informado de la conducta licenciosa de su cónyuge, quien supuestamente mantenía relaciones extramatrimoniales con otra persona y en su domicilio, ofreciendo como medios probatorios las declaraciones testimoniales, documentales y fotografías (...)»; sin embargo, en otra parte se señala que en la audiencia de conciliación se produjo una variación de divorcio por causal a la de separación convencional y divorcio ulterior.

El daño moral puede o no presentarse como producto del adulterio, en el presente caso, de la parte expositiva se desprende que nada se dijo respecto del daño moral, que en un inicio se invocó. Así mismo al no invocarse el daño moral tampoco se demandó al amante para que se haga cargo de la responsabilidad civil. No obstante ello, posteriormente se produjo una variación de divorcio por causal a la de separación convencional.

\subsubsection{Se demanda divorcio por la causal de conducta deshonrosa y en los hechos se menciona el adulterio.-}

Expediente $\mathrm{N}^{\circ}$ : 2008-00837-0-2101-JR-FA-2 (Divorcio por causal) El demandante E. M. interpone demanda de divorcio por la causal de conducta deshonrosa que hace insoportable la vida en común, acumulativamente en forma objetiva, originaria y accesoria las pretensiones de: liquidación de la sociedad de gananciales con adjudicación preferente de los bienes, suspensión de la patria potestad, tenencia de menor e indemnización de daños y perjuicios. Demanda que dirigió contra J. T. de M. (Divorcio por causal, 2008).

En este caso -en un primer momento- se demandó el divorcio por causal de conducta deshonrosa, así se desprende de la parte expositiva de la sentencia, la misma que señala:

«la conducta deshonrosa de la demandada se configura por los actos vergonzosos que efectúa, ya que se conduce de una manera incorrecta, indecente e inmoral, es decir, actúa contra el orden público, la moral y que en el caso de autos con los medios de prueba que anexa a su demanda, se tiene plenamente acreditado que la conducta de la demandada es realmente deshonrosa, a tal caso que viene efectuando constantes actos de infidelidad con 0. G. V. (...)». 
No obstante lo señalado precedentemente, en la misma sentencia se señala que en la audiencia de conciliación se procedió a la variación de la demanda de divorcio por causal a la de separación convencional y divorcio.

Así mismo al variarse la demanda a la de separación convencional y divorcio, no tuvo objeto pronunciarse sobre los daños y perjuicios invocados en un inicio.

\section{Expediente $\mathrm{N}^{\circ}$ : 00030-2008-0-2101-JR-FC-01 (Divorcio por causal)}

El demandante -Á. R. E. T.- interpuso demanda de divorcio por las causales de abandono injustificado de hogar, violencia psicológica, injuria grave, conducta deshonrosa e imposibilidad de hacer vida en común en contra de M. L. C. H. y acumulativamente la disolución de la sociedad de gananciales y la exoneración de la pensión alimenticia a favor de la cónyuge demandada. (Divorcio por causal, 2008).

En el considerando décimo segundo (causal de conducta deshonrosa atribuible a la cónyuge M. L. C. H.) de la sentencia, se dijo:

"Que en la demanda no se invocan en forma ordenada y coherente en que consisten las conductas deshonrosas de la demanda, por lo que no es posible verificar la realidad de dicha causal. Por lo que al no existir precisión de la fecha, circunstancias, lugar y continuidad de estas conductas de la demandada, las menciones vagas y genéricas expuestas por el actor, tampoco han sido acreditadas».

Finalmente se fallo declarando fundada la demanda sobre divorcio por la causal de imposibilidad de hacer vida en común y acumulativamente la disolución de la sociedad de gananciales, así mismo, se declaró infundada la misma demanda en cuanto a la pretensión de Divorcio por las causales de abandono injustificado de hogar conyugal, violencia psicológica, injuria grave, conducta deshonrosa, y la pretensión acumulada accesoria de exoneración de alimentos.

En este caso el demandante invocó actos de infidelidad dentro de la causal de "conducta deshonrosa»; sin embargo, como ya se vio, en la sentencia se declaró infundada la referida causal debido a que no se acreditó la misma.

De otro lado, se puede advertir también que en la demanda no se invocó ninguna clase de daños.

3.1.4 Se demanda divorcio por la causal de adulterio, se pide resarcimiento de daños y perjuicios pero no se demanda al tercero (amante).-

Expediente $\mathrm{N}^{\circ}$ : 01362-2008-0-2101-JR-FC-01 (Divorcio por causal) El demandante pidió la disolución del matrimonio por la causal de separación de hecho y acumulativamente el cese de la obligación alimentaria para con la demandada. (Divorcio por causal, 2008)

De otro lado, G. R. C. M. interpuso demanda reconvencional de Divorcio por las causales de adulterio y conducta deshonrosa que hace insoportable la vida en común y acumulativamente la reparación del daño moral.

Adulterio. En el considerando décimo tercero de la sentencia se dijo:

«De la causal de adulterio. La demandante de la reconvención señala que el adulterio consiste en que L. M. P. tiene una hija extramatrimonial de nombre A.L.M.Q., quien nació en 1996 (lo que evidencia el acceso carnal entre el reconvenido con una persona diferente a su cónyuge al tiempo de la concepción), pero que el reconveniente se enteró de su existencia recién en el año 2009, cuando la notificaron con una demanda de prorrateo de alimentos. El artículo 339 del C.C., indica que la acción basada en la causal de adulterio (entre otras) caduca a los seis meses de conocida la causa por el ofendido y, en todo caso, a los cinco años de producida. De autos se ha acreditado que G. R. C. M. tuvo conocimiento de la convivencia del reconvenido con N. Q. C. desde antes del año 2009 (...). Además, al momento de interponer la demanda reconvencional, han transcurrido al menos trece años de producirse el adulterio; excediendo el plazo largo de cinco años que señala la norma citada».

Reparación del daño moral. En el décimo quinto considerando se dijo: 
«el daño moral debe acreditarse, pues no constituye un automatismo en el fuero interno de las personas, dado que está ligado a las circunstancias de frecuencia, intensidad, manifestaciones psíquicas, somáticas, entre otras características, como por ejemplo la personalidad y recursos de afronte de una persona, lo que significa que conforme a la sensibilidad de cada persona, un hecho puede generar una diversidad de repercusiones, en algunos casos graves y en otros leves, y aun en otros no puede generar manifestación alguna. Es necesario además verificar la magnitud del daño moral, precisamente para los efectos de cuantificar el monto de la indemnización con un criterio sensato y razonable, y no arbitrario.

Sin embargo de lo actuado y probado durante el desarrollo del proceso, no se acredita con ningún medio probatorio que la reconviniente haya padecido sufrimiento, dolor, congoja o alguna otra manifestación psíquica y psicosomática que exteriorice el daño moral, pues este no puede ser considerado implícito».

La demanda reconvencional interpuesta por $G$. R. C. M. en contra de L. M. P. por la causal de adulterio se declaró fundada.

De otro lado, respecto del daño moral invocado, se declaró infundada bajo el argumento que el mismo no se puede presumir y que no fue acreditado.

\subsection{Factores de Atribución Subjetivos}

El artículo $1969^{\circ}$ de nuestro Código Civil señala: «Aquel que por dolo o culpa causa un daño a otro, está obligado a indemnizarlo. El descargo por falta de dolo o culpa corresponde a su autons. Este artículo regula la conocida responsabilidad subjetiva, los criterios de imputación subjetivos, vienen a ser constituidos por la culpa y el dolo.

\subsubsection{El Tercero (amante) y los Factores de Atribución Subjetivos}

\subsubsection{Dolo del tercero (amante):}

En este supuesto existe la intención por parte del tercero (amante) de querer causar el daño. Es decir, el tercero conoce, sabe de la relación matrimonial y no obstante ello decide mantener una relación extramatrimonial con el cónyuge culpable con la intención de provocar un daño en la esfera sentimental del cónyuge inocente. En palabras del profesor Espinoza «el sujeto actúa para provocar una daño» (Espinoza, 2011, pág. 166) se dice que existe una identificación con la noción genérica del dolo penal.

Algo distinto seria el supuesto en el cual el tercero no quiere provocar el daño, pero se representa que su relación extramatrimonial con el cónyuge culpable puede ocasionar un daño al cónyuge inocente y no obstante ello inicia esta relación extramatrimonial.

Este supuesto vendría a constituir el dolo eventual en donde no se actúa para dañar, sino que «el sujeto obra aunque se represente la posibilidad de un resultado dañoso, que no descarta» (Espinoza, 2011, pág. 166).

Ahora -es necesario recordar- el adulterio no se produce por mantener una relación extramatrimonial; sino, por el acceso carnal que uno de los cónyuges tiene con una persona distinta de su cónyuge. Pero debe tenerse en cuenta que al iniciarse una relación extramatrimonial la ocurrencia de relaciones sexuales entre la pareja será altamente probable y ahí si se configura el adulterio.

De otro lado, cabe señalar que ya sea que el daño se produjo por dolo o culpa se debe de resarcir ese daño. Así lo señala también el profesor italiano Scognamiglio (Espinoza, 2011, pág. 166) cuando dice: «si el daño se debió a dolo o culpa, ello no influye de manera alguna en la obligación resarcitoria». En otras palabras la obligación resarcitoria no depende de si el daño se produjo con dolo o culpa.

\subsubsection{Culpa del Tercero (amante):}

El supuesto de la culpa es más complicado de advertir que el del dolo. En efecto, partiendo del hecho que las relaciones sexuales en una relación extramatrimonial es algo posible de que ocurra ¿Cómo podría sostenerse que el tercero incurrió en culpa? El tercero podría alegar que mantuvo relaciones con el cónyuge culpable pero que desconocía totalmente la relación matrimonial pre- 
existente con lo que no pudo representarse un eventual daño al cónyuge inocente, ni mucho menos tener la intención de causar el daño.

Creemos que el tema radica en que la demandante pruebe que el tercero (amante) si pudo haber conocido -siendo diligente- la relación matrimonial pre-existente. Recordemos lo que señalaban los Mazeaud «La culpa cuasidelictuosa es un error de conducta que no hubiera podido cometer una persona advertida colocada en las mismas circunstancias externas que el autor del perjuicio» (Mazeaud, 1976, pág. 204)

Si la demandante prueba que el tercero estuvo en la capacidad de haber conocido la relación matrimonial y no fue diligente, iniciando una relación con su cónyuge-relación en donde hubo el acceso carnal y hasta pudo haber hijos extramatrimoniales- se configura claramente la culpa.

Por su parte el tercero tendrá que demostrar la falta de culpa, tendrá que demostrar que cualquier persona colocada en su lugar bajo las mismas circunstancias externas no hubiese podido advertir la relación matrimonial preexistente.

\subsubsection{Eximentes del Tercero (amante). Ruptura del Nexo Causal:}

Nos referiremos básicamente a dos: el hecho de un tercero y el hecho de la propia víctima.

\section{El hecho de un Tercero:}

En este supuesto la ruptura del nexo causal se da por el hecho de un tercero. En el supuesto del adulterio el tercero (amante) podría invocar la ruptura del nexo causal señalando que el hecho de un tercero fue determinante, por ejemplo asumamos de que el amante -sin saber que es el amante- inicio una relación extramatrimonial con el cónyuge culpable, el mismo que pudo haberla engañado en todo momento indicándole que era una persona libre sin ninguna relación.

Para nuestro ejemplo son los hechos del cónyuge culpable los que inducen al tercero (amante) al error de creer que está iniciando una relación con una persona libre de impedimento matrimonial, con una persona que no está casada.

\section{El hecho de la Propia Víctima:}

Este supuesto se podría presentar por ejemplo cuando es la propia cónyuge inocente la que podría contratar a una persona para que esta tenga acceso carnal con su esposo.

El hecho de la propia "víctima» es la que genera el «daño». Podrá producirse el divorcio por adulterio; pero, de ninguna manera podría configurarse un daño, existe una ruptura del nexo causal.

\section{3 ¿Por qué no se demanda al tercero que coadyuvó al adulterio?}

En los anteriores puntos se ha visto una serie de sentencias de divorcio en donde se hace mención en todas- al adulterio; sin embargo, es preciso señalar que de todas ellas solo una tuvo una sentencia de divorcio por causal de adulterio.

Además, de esta última sentencia -por causal de adulterio- se tiene que los daños y perjuicios que se demandaron acumulativamente fueron declarados infundados. Obviamente en ese proceso no se demandó al tercero (amante) por los daños y perjuicios. De todo esto surge la interrogante ¿por qué no se demanda al tercero que coadyuvó al adulterio? Las respuestas a esta interrogante pueden ser las siguientes:

Demanda de divorcio por adulterio con sentencia por causal de adulterio. Para que se pueda demandar al tercero (amante) por los eventuales daños y perjuicios ocasionados al cónyuge inocente -al margen de los requisitos que deben de concurrir para establecer la responsabilidad civil- es necesario que se presente determinadas circunstancias; esto es, deberá de presentarse una demanda de divorcio por causal de adulterio con su correspondiente sentencia de divorcio por causal de adulterio.

Si el divorcio se produce por otra causal, distinta al adulterio, no tiene sentido hablar de la responsabilidad del tercero, por ejemplo divorcio por imposibilidad de hacer vida en común o separación de hecho. 
En las sentencias reseñadas anteriormente, en la única que pudo hablarse de la responsabilidad del tercero fue en el Expediente $\mathrm{N}^{\circ}$ : 01362-2008-02101-JR-FC-01, (Divorcio por causal, 2008) debido a que fue el único que tuvo una sentencia por causal de adulterio.

Simple omisión. Existe una simple omisión, si se demanda divorcio por causal de adulterio y acumulativamente resarcimiento por daño moral, esta última solo está dirigida contra el cónyuge culpable omitiéndose al tercero. Como se desprende en páginas atrás al desarrollar el artículo $1969^{\circ} \mathrm{C}$.C no existe inconveniente alguno para poder dirigir la demanda -en lo que respecta al daño moral- contra el tercero.

\subsection{Prueba del Adulterio y la Incidencia del Porqué no se Demanda por esta Causal:}

Probar el adulterio es un aspecto importante, en la medida que -como ya lo advertimos anteriormentesi no se prueba el adulterio no se producirá el divorcio por esta causal, por lo que la demanda será declarada infundada o en todo caso podrá variarse la demanda y el divorcio se producirá pero por una causal distinta a la del adulterio, lo cual implicaría que carezca de sentido hablar de la responsabilidad del tercero coadyuvante al adulterio.

Es por ello que la prueba del adulterio tiene una incidencia directa en el tema que nos ocupa, razón por la cual retomamos este tema.

En la doctrina se tiene que el tema de la prueba del adulterio es harto complejo. Se puede afirmar que se tienen dos tipos de prueba del adulterio: las directas y las indirectas o indiciarias, las mismas que desarrollaremos a continuación:

3.4.1 Prueba Directa: Recordemos que el adulterio consiste en el acceso carnal que tiene uno de los cónyuges con una persona distinta a su cónyuge, por lo que la prueba directa consiste en probar el acceso carnal que tuvo el cónyuge culpable con otra persona.

Al respecto el profesor argentino Belluscio afirmaba: «por la índole del hecho, resulta generalmente imposible la prueba directa del adulterio» (Belluscio,
2004, pág. 415), en efecto, dada la naturaleza del hecho existe un alto porcentaje de que el mismo no pueda ser probado en forma directa; pero ello, no implica en modo alguno que no existan otras maneras de poder acreditar el adulterio. Es ahí donde las pruebas indirectas o indiciarias juegan un rol preponderante.

3.4.2 Prueba Indirecta o Indiciaria: En palabras del notable jurista argentino Alvarado Velloso (Alvarado Velloso, 2007, pág. 97) «denominase indicio a un hecho conocido (el indiciario o el indicador) a partir del cual se razona -por inducción o deducción 0 abducción crítica- la existencia de un hecho desconocido (el indicado)».

El mismo jurista señala que el indicio constituye un medio de confirmación (medio de prueba) indirecto que le permite al juez obtener el resultado de una presunción que, a su turno, es el juicio lógico que permite al juzgador tener como cierto o probado un hecho incierto después de razonar a partir de otro hecho cierto.

Así el adulterio se puede probar a través de indicios ciertos, precisos, graves y concordantes. En la casuística argentina (Belluscio, 2004, pág. 444) se han presentado diversos supuestos entre ellos los siguientes:

El nacimiento de hijos extramatrimoniales "CNCiv, Sala A, 24/3/73, LL, 147-167, y ED, 47-433; íd., Sala C, 3/2/83, LL., 1983-C-173; íd., Sala E, 21, 21/3/85, LL., 1985-E-160».

El matrimonio bígamo o celebrado en el extranjero «CNCiv, Sala A, 13/7/00, LL., 2000-F-106; íd., Sala C, 29/12/80, ED, 93-211; íd., Sala D, 3/8/81, ED, 95787».

El aborto producido varios años después de separados de hecho los cónyuges «CCiv 2da Cap, $17 / 5$ y $28 / 5 / 20$, JA $4-279$ y 293».

El concubinato público con un tercero «CNCiv, Sala B, 6/3/97, LL., 1998-D-512; íd., Sala D, 8/7/66, LL, 123-669, y ED, 17-904; íd., Sala J, 12/9/93, ED, 176159». 
El encierro de la mujer durante horas con otro hombre, en ausencia del marido «C 2daCiv Com, La Plata, Sala III, 26/9\%58, JA, 1959-VI-29».

La ocupación de una habitación en un hotel u hospedaje con un tercero «CNCiv, Sala E, 21/3/85, LL., 1985-D-160; CCivCom Rosario, Sala 1, 25/3/43, RepLL, V-640, N 16».

La exhibición reiterada e ininterrumpida del marido con otra mujer, a quien presenta como su esposa, en actitudes propias de amantes «CCivCom Mar del Plata, 17/12/64, RepLL, XXVI-584, Nº72».

Todos los casos fueron extraídos de Belluscio; sin embargo en la doctrina peruana el profesor Varsi (Varsi Rospigliosi, 2012, pág 334) señala supuestos similares «»reconocimiento de un hijo a pesar de ser estéril, el aborto después de una separación de hecho, segundo matrimonio en el extranjero, concubinato público, ocupación u hospedaje con tercero.

Finalmente debemos señalar que nuestro Código Procesal Civil en su artículo 276 prescribe: «El acto, circunstancia o signo suficientemente acreditados a través de los medios probatorios, adquieren significación en su conjunto cuando conducen al Juez a la certeza en torno a un hecho desconocido relacionado con la controversia».

Como se podrá advertir y si bien es cierto que resulta casi imposible aportar prueba directa del adulterio, se puede recurrir a la prueba indirecta o indiciaria que, en estos casos adquiere relevancia. De lo anterior, la falta de prueba directa del adulterio no debe de ser óbice para demandar el divorcio por causal de adulterio, en merito a que también puede apelarse a los medios probatorios indirectos que pueden generar la misma convicción que aquellos.

\subsection{Responsabilidad Solidaria en los Artículos 1978 y 1983 del Código Civil:}

En nuestro Código Civil existen dos artículos que se encuentran relacionados directamente con el objetivo en cuestión, nos referimos a los artículos $1978^{\circ}$ y $1983^{\circ}$.
El art. 1978 prescribe: «También es responsable del daño, aquel que incita o ayuda a causarlo. El grado de responsabilidad será determinado por el Juez, de acuerdo a las circunstancias».

Por su parte el art. 1983 establece: «Si son varios los responsables del daño, responderán solidariamente. Empero, aquel que pagó la totalidad de la indemnización puede repetir contra los otros, correspondiendo al Juez fijar la proporción según la gravedad de la falta de cada uno de los participantes. Cuando no sea posible discriminar el grado de responsabilidad de cada uno, la repartición se hará por partes iguales».

De la lectura a estos dos preceptos normativos se tiene que se puede ser partícipe (incitador 0 ayudante) 0 autor del daño y, prima facie, las consecuencias de ser considerado en uno u otro grupo tiene consecuencias disimiles, por lo que resulta necesario precisar a quién se considera como incitador, ayudante 0 autor. Esto -como ya se dijotiene una trascendental importancia en la medida que las consecuencias no son para todos iguales.

Incitar: Según el Diccionario de la Lengua Española (Real Academia Española, 2014) proviene del latín incitâry que significa «mover o estimular a alguien para que ejecute algo». En palabras de Alfaro cuando comenta el Código Civil de 1984 (Flores, 2013) «la decisión final de la realización del acto es fomentada y apoyada por uno distinto de aquel que la adopta y la ejecuta, por lo tanto, estamos frente a un autor secundario del daño».

Por su parte De Trazegnies (De Trazegnies, 2005, pág. 563) señala: «en realidad, hay que distinguir entre incitar a cometer el daño e incitar a incurrir en negligencia o imprudencia»; es decir, que el artículo 1978 se aplica fundamentalmente al supuesto del dolo y no a una eventual autoría por culpa.

El mismo jurista afirma que: «el tenor literal del propio artículo 1978 nos lleva a pensar en tal sentido, ya que la norma establece: "También es responsable del daño aquel que incita o ayuda a causarlo". Ese "lo" final se refiere al daño mismo, por lo que la norma debe leerse: "También es responsable del daño aquel que incita... a causar el daño" estamos, pues, frente a la situación en que alguien incita a realizar una 
conducta que, a través de una serie de otras causas y concausas, puede terminar en un daño».

Este razonamiento aplicado al daño causado por el adulterio seria más o menos de la siguiente manera: si una persona incita a uno de los cónyuges a que este sea infiel con otra persona a su cónyuge también es responsable del daño.

Ayudar: Proviene del latín adiutâreque significa "prestar cooperación" (Real Academia Española, 2014). Por su parte Flores (De Trazegnies, 2005, pág. 563) afirma que «ayudar» es un verbo más común, que implica sinónimos como colaborar, auxiliar, reforzar la acción de otro sujeto, de modo que el acto ejecutado, no se perfeccione en la misma magnitud si no fuera por la intervención del ayudante.

\subsubsection{Consecuencias de la Distinción entre Partícipes y Autores:}

Que sin embargo muchos autores reconocidos se han detenido a analizar si el partícipes (entiéndase «incitador» o «ayudante») responden de igual manera que los autores; dicho de otro modo, si los partícipes y autores responden solidariamente., tales como Castillo y Osterling, Flores Alfaro, Espinoza Espinoza, Alan Pasco, De Trazegnies entre otros, por nuestra parte nos adherimos a la posición que sostiene que el artículo $1978^{\circ}$ del C.C no establece un supuesto de responsabilidad solidaria. Basamos nuestra posición en el hecho que implicando la responsabilidad solidaria consecuencias graves, no se puede interpretar o hacer extensiva la solidaridad, ella debe de estar expresamente señalada, no debe dejar lugar a dudas. De igual modo, creemos que si la intención del legislador -respecto de los partícipeshubiese sido la de establecer su solidaridad, hubiese bastado la redacción del artículo $1983^{\circ}$, recuérdese lo que señala este artículo: "Si varios son responsables del daño, responderán solidariamente. (...)». Es por ello que, creemos, que al establecer en el artículo $1978^{\circ}$ la responsabilidad del que «incita» 0 «ayuda», el legislador quiso establecer una diferencia entre los autores y los partícipes y, esa diferencia radica en las consecuencias. Es decir, si bien los partícipes también son responsables, estos, no responden solidariamente como si lo hacen los autores.

\subsection{2 ¿El tercero (amante) es incitador, ayudante o co-autor del eventual daño al cónyuge inocente por el adulterio?}

Consideramos que el tercero (amante) -que actúa con dolo o culpa- es co-autor del daño que se le ocasiona al cónyuge inocente como consecuencia del adulterio. Esto en la medida que para que se configure el adulterio es imprescindible la intervención del tercero, no se puede presentar el adulterio sin la intervención de este. El tercero (amante) no es incitador ni ayudante es co-autor. El deber de fidelidad incumplido por el cónyuge, no se hubiese materializado sin la intervención del tercero, es de tal importancia el actuar de este último, que sin su intervención es imposible el adulterio.

No obstante lo anteriormente señalado y dada la división en las posturas sobre la solidaridad entre los partícipes y los autores, es necesario mostrar los dos posibles escenarios dentro de los cuales se podría ubicar al tercero (amante).

\subsubsection{Si se Considera al Tercero (amante) como Ayudante:}

Si al tercero (amante) se le considera como ayudante este responderá de acuerdo al artículo 1978 del Código Civil; es decir, responderá por el daño de manera independiente. Esto desde nuestra posición, asumiendo que el artículo $1978^{\circ}$ C.C no regula un supuesto de solidaridad.

No obstante, como ya lo señalamos, creemos que el tercero (amante) es un co-autor y no un mero ayudante. Ello en la medida que su participación es decisiva para que se configure el adulterio.

\subsubsection{Si se Considera al Tercero (amante) como Co-autor:}

Si es considerado como co-autor del daño que se le ocasiona al cónyuge inocente por el adulterio, será responsable solidario con el cónyuge culpable (posición que asumimos). Consecuencia de ello, será que el cónyuge inocente podrá dirigir la demanda en la parte de responsabilidad civil- contra ambos y pedir el integro del resarcimiento a cualquiera de los dos. 


\subsection{JURISPRUDENCIA}

\subsubsection{Caso Brasileño:}

El caso se presentó en el Estado brasileño de Goias en donde la cónyuge inocente -una profesora universitaria- demandó ante los tribunales brasileños el resarcimiento del daño moral a consecuencia del adulterio.

La decisión judicial favoreció a la demandante, la misma que alegó haber sufrido por la infidelidad de su marido con las humillaciones y las burlas de colegas, familiares y amigos, humillaciones que le obligaron a abandonar su empleo y a asistir a un tratamiento psicológico para poder superar la situación.

Lo curioso del caso es que el marido se mantuvo al margen del proceso. Finalmente el Juez Joseli Luiz da Silva le concedió la suma de 31.500 reales (unos 11.700 euros) por daños morales, monto que debía de pagar la demandada (amante) (diarioinformacion, 2008).

\subsubsection{Caso Americano:}

Este caso sucedió en Carolina del Norte en donde Cynthia Shackelford -casada con Allan Shackelforddemandó a la amante Anne Lundquist por seducir deliberadamente a su marido por la suma de nueve millones de dólares.

Durante el proceso la demandante pudo probar que ella y su esposo estaban profundamente enamorados cuando apareció la amante en escena. Un Tribunal de Greensboro ha hecho lugar a la demanda concediéndole los nueve millones de dólares (www.elmundo.es, 2014).

En este caso, al igual que en le brasilero solo se demandó a la amante y no así al cónyuge.

\subsubsection{Caso Italiano:}

Dos esposos italianos que tuvieron un negocio de televisores: al do Spadavecchia era el titular de la empresa y su esposa lo ayudaba y remplazaba en las ventas, en los viajes que su esposo realizaba por motivos de trabajo. En el año de 1973 contrataron a un dependiente -Sandro Santolomazza- y cuatro años después nació un niño. En 1978 se descubre que faltaba mercadería en el depósito, que no existía correspondencia entre las ventas y lo ganado y, además, que la esposa y el dependiente habían abierto una cuenta corriente mancomunada y, lo peor que existía una documentación escrita, por parte del dependiente, en poder del marido, en el cual se declaraba la relación amorosa y que el niño era fruto de la relación del dependiente y la esposa de Spadavecchia.

El esposo despidió al dependiente -Santolomazzae interpuso una demanda de divorcio por adulterio en contra de la esposa, la misma que fue declarada fundada. Posterior a ello Spadavecchia demandó solo a Santolomazza por daños patrimoniales y morales sufridos por la relación adulterina, el monto de la demanda ascendía a 100 millones de liras. El tribunal de Roma -10 años después- fallo declarando infundada la demanda.

La demanda fue declarada infundada básicamente porque el demandante no probó la existencia del daño patrimonial consecuencia de la infidelidad de la mujer, sino también porque no había proporcionado ninguna prueba del nexo causal entre la actividad de Santolomazza y el adulterio de la mujer.

El profesor peruano Espinoza al comentar este caso señala que en nuestro ordenamiento jurídico el cónyuge, en caso de divorcio, puede solicitar judicialmente una indemnización por el daño moral que le ha sido ocasionado por la pareja de acuerdo al artículo 351. Cabe entonces la posibilidad que, al producirse este daño (que tampoco debe limitarse al «daño moral», sino hacerse extensivo al «daño a la persona»), se configure un supuesto de co-autoria, incitación o ayuda, con la dificultad, de orden práctico, de distinguirlos (Espinoza, 2011, pág. 227).

Coincidimos con el citado profesor en que el resarcimiento no debe de limitarse al «daño moral»; por el contrario debe de hacerse extensivo al «daño a la persona» en la medida que este último es más genérico y engloba otro tipo de daños como el «daño al proyecto de vida». De otro lado -como ya se indicó páginas atrás- creemos que el daño que ocasiona el cónyuge culpable con el tercero (amante) es un supuesto de co-autoria. 


\section{CONCLUSIONES}

PRIMERA: Se ha comprobado que conforme al artículo 1969 del Código Civil el tercero (amante) sí debe de responder por el daño que se le ocasione al cónyuge inocente. Esto en razón a que todo aquel que ocasione un daño a otro por dolo o culpa debe de resarcirlo, y el tercero que tuvo la intención de causar un daño al cónyuge inocente o que pudo haberlo previsto y no obstante ello decidió interferir en la relación matrimonial debe de resarcir los daños que su conducta ha causado.

Cabe precisar que, si el tercero también fue engañado por el cónyuge culpable y no tuvo la intención ni la posibilidad de prever el daño al cónyuge inocente no será responsable.

SEGUNDA: Se ha verificado que el tercero (amante) co-responsable con el cónyuge culpable sí deben de responder solidariamente por el «daño a la persona» que se le ocasione al cónyuge inocente como consecuencia del adulterio que desemboca en un proceso de divorcio. No obstante que el deber de fidelidad es de observancia obligatoria solo para los cónyuges; sin embargo, para que la infidelidad -y el consecuente daño- se produzca es determinante la conducta del tercero (amante), es por ello que ambos deben de responder solidariamente.

TERCERA: Se ha comprobado que no se presenta casos de divorcio por adulterio en razón a que su probanza es difícil y si no hay demandas de divorcio por adulterio no habrá proceso dentro del cual se pueda hablar de la responsabilidad solidaria del cónyuge culpable con el tercero (amante). Esto es importante porque un tema probatorio puede llevar a la ausencia de demanda por causal de adulterio y su consecuente resarcimiento.

\section{BIBLIOGRAFÍA}

Alvarado Velloso, A. (2007). Prueba Judicial. Rosario: Libreria Juris.

Belluscio, C. (2004). Manual de Derecho de Familia ( $7 \mathrm{ma}$ Edición. ed.). Buenos Aires: Astrea.

De Trazegnies, F. (2005). La responsabilidad extracontractual (7ma. Edición ed.).
Lima: Fondo Editorial de la Pontifica universidad Católica del Perú.

Divorcio por causal, Expediente $\mathrm{N}^{\circ}$ 2000-0226-212101-JF-01 (Juzgado de Familia 2000). Divorcio por causal, Expediente $\mathrm{N}^{\circ}$ 2004-02504-0211-JR-FA-2 (Juzgado de Familia 2004).

Divorcio por causal, Expediente $\mathrm{N}^{\circ}$ 2008-00837-02101-JR-FA-2 (Juzgado de Familia 2008).

Divorcio por causal, Expediente $\mathrm{N}^{\circ}$ 00030-2008-02101-JR-FC-01 (Juzgado de Familia 2008).

Divorcio por causal, N $01362-2008-0-2101-J R-F C$ 01 (Juzgado de Familia 2008).

Divorcio por causal, Expediente $\mathrm{N}^{\circ}$ 01362-2008-02101-JR-FC-01 (Juzgado de Familia 2008).

Espinoza, J. (2011). Derecho de la Responsabilidad Civil (6ta. Edición. ed.). Lima: Rodhas.

Flores, C. A. (2013). El Código Civil Comentado, la responsabilidad por incitación 0 coautoría. Lima: Gaceta Jurídica.

Información, D. (2008). www.diarioinformación.com. Obtenido de "condenan a una mujer brasileña a indemnizar a la esposa de su amante»: www.diarioinformación.com

Mazeaud, H. y. (1976). Compendio del Tratado Teórico y Práctico de la Responsabilidad Civil Delictuosa y Contractual. México D.F: Colmex.

Real Academia Española, D. d. (14 de enero de 2014). www.rae.es. (R. A. Española, Productor) Obtenido de Diccionarios.

Varsi Rospigliosi, E. (2012). Tratado de Derecho de Familia (Vol. Tomo II). Lima: Gaceta Jurídica.

www.elmundo.es. (14 de enero de 2014). Obtenido de Millonaria por desamor 2010: www.elmundo.es 